\title{
EDITORIAL
}

\section{Brain, Mind and Language Functional Architectures}

\author{
Andrew A. Fingelkurts*, ${ }^{*}$, Alexander A. Fingelkurts ${ }^{1}$ and Giorgio Marchetti*,2,3 \\ ${ }^{1}$ BM-Science - Brain and Mind Technologies Research Centre, P.O. Box 77, FI-02601, Espoo, Finland; ${ }^{2}$ Mind, \\ Consciousness, and Language research net, Italy; ${ }^{3}$ University of Urbino, Urbino PU, Italy
}

\begin{abstract}
The interaction between brain and language has been investigated by a vast amount of research and different approaches, which however do not offer a comprehensive and unified theoretical framework to analyze how brain functioning performs the mental processes we use in producing language and in understanding speech. This Special Issue addresses the need to develop such a general theoretical framework, by fostering an interaction among the various scientific disciplines and methodologies, which centres on investigating the functional architecture of brain, mind and language, and is articulated along the following main dimensions of research: (a) Language as a regulatory contour of brain and mental processes; (b) Language as a unique human phenomenon; (c) Language as a governor of human behaviour and brain operations; (d) Language as an organizational factor of ontogenesis of mentation and behaviour
\end{abstract}

Keywords: Mental categories, consciousness, linguistic thought, language, attention, mental operations, brain areas, cognition.

\begin{abstract}
"Huge benefit of a human which has a developed language lays in the world doubling. With the help of language which designate objects, he [human] can operate with objects which are not perceived directly and which do not belong to his experience ... Human has a double world which includes the world of directly reflected objects and the world of objects, relations and properties which are designated by words. Thus, the word is a special form of reality reflection. Human can voluntary name these images independently from their real existence ... can voluntary control this second world" (Luria in Ref. [1], p.37)

“... a theory of language acquisition requires not only an understanding of signal processing abilities, but also of how these cues affect the innate linguistic endowment. The nature of the language endowment, once precisely established, will guide us towards an understanding of the biological foundation of language, and thus will clarify why we diverge so significantly from other primates. This in turn, will hopefully lead us to formulate a testable hypothesis about the origin and evolution of natural language." (Mehler in Ref. [2], p.277)
\end{abstract}

\section{TIME TO REVIEW}

An enormous number of research publications has been dedicated to the brain-language interaction issue and therefore not surprisingly the subject has become "saturated". Many psychologists have adopted a viewpoint that ignores

*Address correspondence to these authors at the BM-Science - Brain \& Mind Technologies Research Centre, Finland,

E-mail: andrew.fingelkurts@bm-science.com

and Mind, Consciousness, and Language research Net, Italy,

E-mails: Giorgio.marchetti@nsn.com;

info@mind-consciousness-language.com the complexity of brain-language architecture and assumes that by focusing exclusively on speech perception and production, a functional account of how language is processed will follow. At the same time, behavioural scientists believe that it is sufficient to study how language production and perception unfold during development to understand how syntax (or semantics) arises in the infant's mind. Neuroscientists and psycholinguists (see for example ref. [3-7] have acquired extensive knowledge on the physical structures of the brain in relation to language production and processing. However, this knowledge by itself has so far not been able to provide a comprehensive picture of how brain functioning performs the mental processes we use in producing language and in understanding speech; instead it has just begun to reveal some specific elements of the interaction between brain and language.

The multiplicity and inconsistency of the various approaches therefore suggest the need to develop a general theoretical framework that allows researchers to handle the enormous amount of diverse observations related to brainlanguage interaction. It follows that neuroscientific knowledge should be complemented by the knowledge from the various fields of linguistics and related research fields (psycholinguistics, sociolinguistics, semantics, discourse analysis, etc.).

\section{THE IMPORTANCE OF JOINT BRAIN-LANGUAGE STUDIES}

What should this theoretical framework look like to adequately support phenomenal (mental), linguistic (neurolinguistic) and neurophysiologic data? We believe it should be a framework centred on the functional architecture of brain, mind and language.

To foster this view, we have prepared this Special Issue "Brain, Mind and Language Architectures: Where we are 
now?", in which we collate the numerous and diverse approaches to brain and language into a comprehensive body of knowledge, articulated along what we believe to be the main dimensions of research: (a) Language as a regulatory contour of brain and mental processes; (b) Language as a unique human phenomenon; (c) Language as a governor of human behaviour and brain operations; (d) Language as an organizational factor of ontogenesis of mentation and behaviour.

\section{Language as a Regulation Contour of Brain and Mental Processes}

According to the tradition of the Russian psychophysiological school founded by Luria (ref. [8]) and Vygotsky (see ref. [9]) psychology as systemic property of physiology can be studied only by considering the special genesis of all mental functions - the "regulation language contour" which is the highest level of the brain organization of all mental processes. This idea was supported by the work of another great Russian psychophysiologist Ukhtomsky [10] who developed the concept of higher cortical dominantas where language/speech is considered as a cortical dominanta of a special kind which can change the whole behaviour of the human. Indeed, from neuropsychology we know that during aphasia not only is speech disturbed but the whole behaviour of the patient also changes. For example, such patients are characterized by the disruption of higher forms of action.

Recent studies bring experimental evidence that language can restructure cognition [11,12]. Findings from recent neuroimaging studies suggest that activation of the speech motor system during lipreading enhance speech perception by tuning, in a top-down fashion, speech-sound processing in the superior aspects of the posterior temporal lobe (see contribution of Jääskeläinen to this Special Issue). Kobayashi et al. [13] demonstrated that people recruit different linguistic and cognitive resources depending upon the language used to process Theory of $\operatorname{mind}^{1}$, thus suggesting that switching language switches mind (see contribution of Kobayashi Frank to this Special Issue). From an evolutionary point of view, the progressive evolution of language from a simple form to a more sophisticated one (speech, writing, mathematics, science, computing and finally the Internet) can be seen as a response to the chaos of the information overload that each form of language contributed to generate: a response based essentially on a continuous re-shaping and development of human cognitive capacities (see contribution of Logan to this Special Issue).

\section{Language as a Unique Human Phenomenon}

Besides the fact that language/speech plays an important role as a regulation contour of all mental processes, it is also a unique human phenomenon [2,14]. According to Vygotsky $[9,15]$ the human brain is characterized by specific relations between structural and functional units of neural activity which are mediated by language/speech (high cortical dominantas by Ukhtomsky [10]). Thus, the human brain has a new systemo-localisation principle according to which it became an organ of human consciousness. Specifics of

\footnotetext{
${ }^{1}$ Theory of mind (ToM) - the ability to understand mental states of others (such as belief, desire, intention and knowledge) that enables us to explain and predict the behaviour of others.
}

dominant mechanisms of the human brain are determined by extracortical genesis and ontological development of the human mind on the basis of new semantic codes of information perception and processing [16].

Experimental evidence, reviewed by Mehler et al. [2], suggests that only humans, and no other animals, acquire the language spoken in the surrounds and only human infants use the acoustic properties of speech to acquire grammar. Even though apes and also dogs have 'lexicons' that can attain a few dozen words $[17,18]$, such abilities are insufficient to enable non-human animals to construct a grammar comparable to that of humans. 'Ape language' should not be called a language, because there is no convincing evidence of syntactic structures or word orders in ape language. According to critical assessment of a chimpanzee's signs, the mean length of each utterance is no more than 1.6 words, and even longer utterances lack rule-governed combinations of signs [19]. Even when trained to use communication systems, apes, dolphins or parrots do not master anything remotely approaching the power and versatility of human language. One of the most obvious differences is the almost total lack of what George Miller [20] called combinatorial productivity - our ability to recombine words or syllables in new ways to derive entirely new meanings. And none of these communication systems have more than tiny amounts of syntax, whereas grammatical rules of one sort or another are universal in human languages (a mathematical explanation - based on a joint thought -language architecture - of why animals do not talk and think as people do, is given by Perlovsky and Ilin in this Special Issue).

\section{Language as a Governor of Human Behaviour and Brain Operations}

Language is not only means of communication and the basis for verbal, discursive thinking, but also an important means of governance of human behaviour. Language mediates different components of practical actions [21]. For example, the grammatical class of words affects visual analysis and motor control differently [22]. Moreover, language/speech creates new forms of attention, memory, imagination, thinking and action. In other words, the system of words is a powerful factor which forms mental activity [15]. Inner speech ${ }^{2}$ has been shown to be involved in such important processes for behaviour as verbal self-guidance and self-regulation [24], problem-solving [25], planning [26], and memory [27]. Some psychological disorders such as anxiety and depression are mediated by dysfunctional self-talk [28] (for a review, see Ref. [29]).

Recent findings support the simulation based theories of language processing in an embodied framework ${ }^{3}$, and provide a strong reason to link findings from the cognitive neuroscience of language processing to the neurophysiology of eye (and generally motor) movement behaviour (see contribution of Singh and Mishra to this Special Issue).

Word as a "signal of signals" [31] is mediated by a strong dominanta' mechanism (Ref. [10], p. 259). Heard or verbalized word creates a special dominant setting of integrated

\footnotetext{
${ }^{2}$ Inner speech is usually defined as the activity of silently talking to oneself [23]

${ }^{3}$ Embodied and simulation based approaches to language comprehension predict that comprehension of language triggers mental simulation of events and objects as described in the language [30]
} 
brain areas; this dominant setting constitutes a new integral subjective image and forms simultaneous modification of perception $[10,32]$. These and many other observations point to the joint brain-thought-language functional architecture. For the elaboration of this issue see contribution of Benedetti, Marchetti, Fingelkurts and Fingelkurts to this Special Issue. Mathematical modelling of joint thoughtlanguage architecture resolves long-standing issues as to how the brain learns correct words-object associations; and explains a contradiction between human ability for rational thoughtful decisions and the irrationality of human thinking (see contribution of Perlovsky and Ilin to this Special Issue).

It is important to note that structures of consciousness as a "reflection of reflection" in some sign form do not simply isomorphically duplicate the initial content, but add to and enrich it by introducing new connections and relations. Behind the word there is a collective public experience which is concentrated in the crystallized form of meaning [33]. Due to language humans can acquire a knowledge of each other and the experience of previous generations (see contribution of Logan to this Special Issue). The existence of grammatical language structures which are isomorphic to action structures enables humans to perform mental experimenting and to acquire new knowledge mentally.

\section{Language as an Organizational Factor of Ontogenesis of Mentation and Behaviour}

During ontogenesis new psychological systems are formed on the basis of verbalization of attention, memory, actions and thinking: for example, some aspects of language highly influence the development of Theory of Mind capacities (see the contribution by Kobayashi Frank to this Special Issue). Thus, according to Vygotsky [15] after a child has developed a language, he/she adds to the first-order stimuli (manipulation of objects), stimuli of the second-order, which are not the objects themselves, but are the means for organizing and planning human behaviour. This process results in a total reconstruction of all the mental functions of a human, giving him/her freedom of behaviour in relation to situation. Hence, the human being is freeing himself from the property of animal perception - being a "slave of a visual field". With the help of "planning speech" the conception about future (an actual future field) is inserted in human activity and, thus, behavioural impulsivity is controlled. Human conscious awareness, according to Vygotsky [15], is characterized by the fact that it is not based on the limitations imposed by the simultant structure of the visual field (which is a characteristic of animal cognition), but rather by the successive structure of "the verbalized dynamic field of attention" which is achieved on the basis of inclusion of the regulation speech contour: the "attention field" is separated from the "perception field" and is unfolding in time dynamics.

New forms of human behaviour are originated on the basis of inclusion of speech formulas of past and present situations in a single focus of attention. "Speech forms operation based on laws that are different from those characteristic of actual action: it joints, unites, synthesizes past and present" (Ref. [9], p. 48). "Thus, the sign initially acts as a means of social connection in the behaviour of the child, as

\footnotetext{
${ }^{4}$ The planning function of language $[1,8]$ has been discussed and elaborated by Das's group [34]
}

an intermental function; subsequently it becomes a means of controlling his/her own behaviour and he/she just transfers the social relation to a subject inward into his personality" (Ref. [9], p. 41).

A review of experimental evidence [2] suggests that humans are endowed with a species-specific disposition to acquire natural language. Thus, irrespective of whether the learner is hearing and seeing, deaf or even blind, he/she will still attain a grammar that is as rich and complex as we expect it in humans without sensory filters (see $[35,36]$ amongst others). Moreover, the infant's brain preferentially processes speech, rather than non-speech stimuli [37]. And, finally, the work of Dehaene-Lambertz et al. [38] showed that responsible cortical regions are active well before the infant has acquired the native language.

\section{AIM OF THE SPECIAL ISSUE}

The objective of this Special Issue is to collect a compendium of articles which would help to bridge the gap between higher-order reflective or linguistic thought, semantic processing and brain activity. A key goal of this Special Issue is to foster interaction among neuroscientists and linguists and promote the development of cutting-edge ideas related to research issues on Brain, Mind and Language Architectures.

Contributions from leading experts of the field provide a cutting-edge review of this challenging frontier of neuroscience. We hope it will help interested researchers become familiar with research achievements and open new directions. It should also help to stimulate the interest of scientists to design new experiments and devise new concepts.

\section{REFERENCES}

[1] Luria AR. The Making of Mind: A Personal Account of Soviet Psychology. Cambridge: Harvard University Press 1979a.

[2] Mehler J, Nespor M, Shukla M, Peña M. Why is language unique to humans? In Proceeding of Novartis Foundation Symposium 270: Percept, decision, action: bridging the gaps. Chichester: Wiley 2005; pp. 251-284.

[3] Pulvermüller F. The Neuroscience of Language. On Brain Circuits of Words and Serial Order. Cambridge: Cambridge University Press 2002.

[4] Friederici AD. Towards a neural basis of auditory sentence processing. Trends Cogn Sci 2002; 6: 78-84.

[5] Baggio G, Van Lambalgen M, Hagoort P. Language, Linguistics, and Cognition. In: Stokhof M, Groenendijk J, Eds. Handbook of Philosophy of Linguistics. Amsterdam: Elsevier in press.

[6] Hagoort P, van Berkum J. Beyond the sentence given. Phil Trans R Soc B: Biol Sci 2007; 362: 801-11.

[7] Stowe LA, Haverkort M, Zwarts F. Rethinking the neurological basis of language. Lingua 2005; 115: 997-1042.

[8] Luria AR. Language and Consciousness. Moscow: Nauka 1979b.

[9] Vygotsky LS. The Collected Works of L.S. Vygotsky - Vol. 6. Scientific Legacy. New York: Kluwer Academic/Plenum Publishers 1999.

[10] Ukhtomsky AA. The Dominant. Moscow-Leningrad: Nauka, 1966.

[11] Majid A, Bowerman M, Kita S, Haun DBM, Levinson SC. Can language restructure cognition? The case for space. Trends Cogn Sci 2004; 8: 108-14.

[12] Talmy L. Toward a cognitive semantics. Cambridge: The MIT Press 2000.

[13] Kobayashi C, Glover GH, Temple E. Switching language switches mind: linguistic effects on developmental neural bases of 'Theory of Mind'. Soc Cogn Affect Neurosci 2008; 3: 62-70.

[14] Sakai KS, Homae F, Hashimoto R. Sentence processing is uniquely human. Neurosci Res 2003; 46: 273-9.

[15] Vygotsky LS. The history of the development of high mental functions. Development of the higher mental functions. In: Leontiev A, 
Luria A, Smirnov A, Eds. Psychological Research in the USSR. Moscow: Progress Publishers 1982; vol. 2: pp. 361-366.

[16] Pavlova LP, Romanenko AF. Systemic Approach to Psychophysiological Investigation of Human Brain. Leningrad: Nauka, 1988.

[17] Premack D. Language in chimpanzee? Science 1971; 172: 80822.

[18] Premack D. Gavagai! Cambridge, MA: MIT Press/Bradford Books 1986.

[19] Terrace HS. Nim: A Chimpanzee Who Learned Sign Language. New York: Alfred A. Knopf 1980.

[20] Miller GA. The Psychology of Communication. New York: Basic 1967.

[21] Tihomirov OK. Psychology of Thinking. Moscow: Nauka 1984.

[22] Gentilucci M, Benuzzi F, Bertolani L, Daprati E, Gangitano M. Language and Motor Control 2000; 133: 468-90.

[23] Zivin G. Removing common confusions about egocentric speech, private speech, and self-regulation. In: Zivin G, Ed. The Development of Self-regulation Through Private Speech. New York: Wiley 1979.

[24] Harris KR. Developing self-regulated learners: the role of private speech and self-instructions. Educ Psychol 1990; 25: 35-49.

[25] Roberts RN. Private speech in academic problem-solving: A naturalistic perspective. In: Zivin G, Ed. The Development of Selfregulation Through Private Speech. New York: Wiley 1979.

[26] Meacham JA. The role of verbal activity in remembering the goals of actions. In: Zivin G, Ed. The Development of Self-regulation Through Private Speech. New York: Wiley 1979.
Beontiev AA. The Word in Speech Activity. Moscow. Nauka 1965.

[34] Bournot-Trites M, Jarman RF, Das JP. Luria's language theory within a cognitive theory: a Canadian perspective. Aphasiology 1995: 9: 123-35.

[35] Klima ES, Bellugi U. The Signs of Language. Cambridge, MA: Harvard University Press 1979.

[36] Landau B, Gleitman LR. Language and Experience: Evidence from the Blind Child. Cambridge, MA: Harvard University Press 1985.

[37] Mehler J, Jusczyk P, Lambertz G, Halsted N, Bertoncini J, AmielTison C. A precursor of language acquisition in young infants. Cognition 1988; 29: 143-78.

[38] Dehaene-Lambertz G, Dehaene S, Hertz-Pannier L. Functional neuroimaging of speech perception in infants. Science 2002; 298: 2013-5.

\section{(C) Fingelkurts et al.; Licensee Bentham Open.}

This is an open access article licensed under the terms of the Creative Commons Attribution Non-Commercial License (http://creativecommons.org/licenses/by-nc/3.0/) which permits unrestricted, non-commercial use, distribution and reproduction in any medium, provided the work is properly cited. 